DOI: http://10.18315/argumentum.v12i2.29165

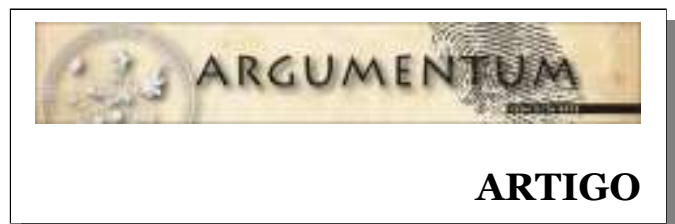

\title{
Caracterização das internações nos leitos de saúde mental em hospital geral
}

\author{
Mental Health beds characterization in general hospital
}

Vanderléia SCHINEMANN*

https://orcid.org/o000-0002-3885-1666

Gustavo ZAMBENEDETTI**

https://orcid.org/o0o0-0002-7372-9930

\begin{abstract}
Resumo: No cenário da reforma psiquiátrica identificam-se propostas de reconfiguração do lugar e do modelo de atenção que perpassa o dispositivo da internação. Entretanto, há resistências para sua efetivação, constituindo a internação como um importante objeto de análise e reflexão. Esse artigo objetiva caracterizar as internações ocorridas nos Leitos de Saúde Mental em um Hospital Geral de um município do interior do Paraná, no período de setembro/2014 a dezembro/2017. Trata-se de um recorte analítico de uma pesquisa quanti-qualitativa com viés descritivo, sob a abordagem teórico-metodológica da Análise Institucional. Destacamos algumas potências desse serviço como o fato de encontrarem-se territorializados, com tempo médio de internação inferior a 7 dias e com baixo número de reinternações e de transferências para outros serviços.
\end{abstract}

Palavras-chave: Leitos de Saúde mental. Internação. Reforma Psiquiátrica. Rede de Atenção Psicossocial.

Abstract: In the context of psychiatric reform there are proposals for reconfiguring the location and model of care, to move beyond hospitalisation. But there is resistance to their implementation, making hospitalisation an important subject for analysis and reflection. This article aims to characterise admissions to Mental Health Beds in General Hospitals in the interior of Paraná from September 2014 to December 2017. It is an analysis based on qualitative descriptive research using the Institutional Analysis theoreticalmethodological approach. We highlight some strengths of this service, such as the fact that it is regionalised, and has an average hospital stay of less than 7 days with low numbers of readmissions and transfers to other services.

Keywords: Mental Health Beds. Hospitalisation. Psychiatric Reform. Psychosocial Care Network.

Submetido em: 30/3/2020. Revisado em: 9/6/2020. Aceito em: 14/7/2020.

* Assistente Social. Doutoranda pelo Programa de Pós-Graduação Interdisciplinar em Desenvolvimento Comunitário da Universidade Estadual do Centro-Oeste. (UNICENTRO, Irati (PR), Brasil). Assistente Social na Prefeitura Municipal de Prudentópolis (PR). Rua São Josafat, 835, Centro, Prudentópolis (PR), CEP.: 84400-0oo. E-mail: vandisch@hotmail.com.

** Psicólogo. Doutor em Psicologia Social e Institucional. Professor do Departamento de Psicologia e do Programa de Pós-Graduação Interdisciplinar em Desenvolvimento Comunitário da Universidade Estadual do Centro-Oeste. (UNICENTRO, Irati (PR), Brasil). Rua Professora Maria Roza Zanon de Almeida Engenheiro Gutierrez, Irati (PR), CEP.: 84505-677. E-mail: gugazam@yahoo.com.br. Commons Atribuição 4.0 Internacional (https://creativecommons.org/licenses/by/4.o/deed.pt_BR), que permite copiar e redistribuir o material em qualquer suporte ou formato, bem como adaptar, transformar e criar a partir deste material para qualquer fim, mesmo que comercial. O licenciante não pode revogar estes direitos desde que você respeite os termos da licença.

Argum., Vitória, v. 12, n. 2, p. 141-164, maio/ago. 2020. | ISSN 2176-9575 


\section{Introdução}

internação e o dispositivo hospitalar, historicamente, foram perpassados por A funções híbridas, podendo servir tanto ao cuidado em saúde quanto ao controle e segregação. Segundo Desviat (2015), a associação da internação com o dispositivo

manicomial serviu a três funções. A primeira delas é a médica, visando uma pretensão terapêutica, apesar desta ser questionada desde seu surgimento. A segunda, uma função social, visto que o manicômio também serviu como refúgio aos loucos pobres. Por fim, a função de proteção da sociedade, local para onde poderiam ser enviados aqueles com os quais a sociedade tem medo ou dificuldade para lidar.

Em diversos países o modelo manicomial, centrado na assistência realizada em hospitais psiquiátricos, passou a ser questionado a partir de meados do século XX. No Brasil, esse questionamento emergiu de forma mais acentuada a partir do final da década de 1970, tendo como desdobramento o surgimento de propostas substitutivas (VASCONCELOS, 2016).

Na proposta da Reforma Psiquiátrica Brasileira (RPB), o Hospital Geral (HG) é considerado como fundamental nesse processo (DIAS; GONÇALVES; DELGADO, 2010). Porém, não como um fim em si mesmo, mas como parte de uma rede com diversos serviços qualificados para o acolhimento das pessoas com sofrimento psíquico, como parte das perspectivas de mudanças propostas pela RPB, a partir das dimensões epistemológica, técnico-assistencial, jurídico-política e sociocultural (AMARANTE, 2007). Portanto, a RPB não está vinculada apenas à implantação de serviços, mas propõe mudanças de paradigmas, de concepções de saúde mental, configurando-se num processo em constante transformação, apresentando tensões, aproximações, contradições, conflitos, que estão simultaneamente se entrelaçando.

O HG é uma estrutura física já existente em vários municípios, constituindo-se como um serviço geograficamente bem localizado no território e no contexto da vida social dos sujeitos, desenvolvendo diversos serviços, como atendimentos de urgência e emergência e clínica médica (BRASIL, 2015). E, sendo assim, direta ou indiretamente já atende pessoas em sofrimento psíquico, seja pela motivação inicial desse sofrimento ou por alguma questão clínica. Portanto, o que nos é relevante é a questão da saúde mental estar no HG, produzindo um movimento nesse espaço e nesse território, que deve ser no sentido de consolidação de um referencial de rede, proporcionando cuidado de forma integral e universal (DIAS; GONÇALVES; DELGADO, 2010).

O atendimento de situações de sofrimento psíquico no HG no Brasil não é recente, aparecendo já em 1954 com a criação das primeiras Unidades de Psiquiatria em Hospital Geral (UPHG). As UPHG tiveram inicialmente suas ações limitadas ao atendimento de demandas específicas de determinadas camadas da população, como militares e previdenciários e, também, limitaram-se a finalidade específica de ensino (BOTEGA, 2017; HILDEBRANDT; ALENCASTRE, 2001; MARCHEWKA, 2007). As UPHG surgiram como 
alternativa aos internamentos nos grandes hospitais psiquiátricos, tendo menos leitos, com menos tempo de hospitalização e indicação de atendimento multidisciplinar (BOTEGA, 2017; HILDEBRANDT; ALENCASTRE, 2001; MARCHEWKA, 2007).

Em 1992, através da Portaria da Secretaria de Atenção à Saúde do Ministério da Saúde (SAS/MS) n. 224, foram apresentadas diretrizes e normas para diversos tipos de atendimentos, entre eles os leitos psiquiátricos no hospital geral (BRASIL, 1992). E, na sequência, foram sancionadas outras portarias ministeriais (BRASIL, 2002a, 2002b, 2004, 2009) que tinham o objetivo de melhorar a qualidade de assistência dos serviços hospitalares de forma geral, preconizando o fechamento de leitos em hospitais psiquiátricos e a abertura de serviços substitutivos (VASCONCELOS, 2016).

No ano de 2011, foi instituída a Rede de Atenção Psicossocial (RAPS) através da Portaria do MS n. 3088 (BRASIL, 2011), reforçando-se a necessidade de organização dos serviços em rede, seguindo a lógica do Sistema Único de Saúde (SUS) e da RPB que já preconizavam o trabalho em rede. Contudo, a introdução dessa portaria busca dar um caráter de institucionalidade à rede, fomentando a implantação e articulação de diversos pontos de atenção. Além dos Centros de Atenção Psicossocial (CAPS), caracterizados como serviço estratégico na constituição da RAPS, outros componentes de atenção são elencados visando dar conta da proposta de integralidade, intersetorialidade e universalidade do atendimento em saúde mental, como a atenção básica em saúde, atenção psicossocial especializada, atenção de urgência e emergência, atenção residencial de caráter transitório, atenção hospitalar, estratégias de desinstitucionalização e reabilitação psicossocial (BRASIL, 2011).

Seguindo nessa lógica de inversão do modelo manicomial, o componente hospitalar foi regulamentado através de um conjunto de portarias (BRASIL, 2012a, 2012b, 2012c, 2012d), passando a se chamar Serviço Hospitalar de Referência para atenção a pessoas com sofrimento ou transtorno mental e com necessidades de saúde decorrentes do uso de álcool, crack e outras drogas - Leitos de Saúde Mental em Hospital Geral (LSMHG)1. Com isso, ficou estabelecido que a assistência deveria ser prestada no menor tempo possível, estando articulada e integrada aos outros serviços da rede extra-hospitalar, em regime integral, por vinte quatro horas diárias e em todos os dias da semana. Visou-se à construção de um projeto terapêutico amplo, que contemple as necessidades do sujeito e a continuidade do cuidado após a internação.

De acordo com Dias, Gonçalves e Delgado (2010) e confirmado por Monteiro (2013), observa-se que há, no Brasil, duas forças contrastantes e que se manifestam objetivamente na apropriação do espaço do HG: a Reforma Psiquiátrica e a Psiquiatria Clínica, que representam, respectivamente, o modelo de atenção psicossocial e o modelo manicomial.

1 Leitos de Saúde Mental em Hospital Geral - Nomenclatura utilizada pela Área Técnica de Saúde Mental, Álcool de Outras Drogas/DAPES/SAS/MS, conforme consta na Nota Técnica n ${ }^{0} 25$ de 05 de junho de 2012 (BRASIL, 2012c). 
Entre os atores envolvidos nessa disputa de modelos, “[...] há grupos de interesses fundamentalistas e neoliberais que ameaçam e atacam toda uma conjuntura de luta política e social exercida pelo processo de democratização histórico da RPB" (SOUZA; JORGE, 2019, p. 16). Dentre suas propostas destacam-se a manutenção dos Hospitais Psiquiátricos (HP), implantação e manutenção de unidades ou enfermarias de psiquiatria.

Esses aspectos adquirem relevância diante do contexto atual, em que se apresenta a nova portaria $^{2}$ do MS, que incluem como mais um componente da rede os HP e aumentam o repasse de recursos para internamentos psiquiátricos, possibilitando internamentos superiores há 90 dias, em HP com mais de 400 leitos. Sinalizam ainda, a possibilidade de custeio de procedimentos invasivos como a eletroconvulsoterapia, além de propiciarem o aumento do número de leitos em HG e a obrigatoriedade da presença na composição da equipe de um médico psiquiatra, entre outros aspectos que nos levam a refletir sobre quais poderão ser os reflexos produzidos no movimento da reforma psiquiátrica brasileira.

Diante dessas recentes modificações na Política Nacional de Saúde Mental, é necessário dar continuidade às discussões sobre o lugar, a função e o modelo sob o qual a internação deve compor a RAPS. Souza e Jorge (2019) destacam a importância de colocar em evidência a discussão sobre o HP nessa política, que até então encontrava-se em invisibilidade. Também é necessário reafirmar os propósitos da RP, em relação à progressiva extinção dos HP e a implantação de serviços substitutivos comunitários, visando à consolidação de um modelo de atenção psicossocial de base territorial. De 2002 à 2014, houve uma redução de aproximadamente 50\% do número de leitos SUS em HP, passando de 51.393 leitos para 25.988 (BRASIL, 2015).

Quanto ao número de LSMHG, no ano de 2014, somavam-se 888 leitos, distribuídos em 187 HG, nas diversas regiões do país (BRASIL, 2015). No Estado do Paraná, de acordo com o Cadastro de Estabelecimentos de Saúde (CNES), constatou-se que até o mês de janeiro de 2019 haviam 2.646 leitos psiquiátricos (em HP), 201 Leitos Clínicos de Saúde Mental (em enfermarias, as antigas UPHG) e apenas 21 LSMHG, sendo que desse total, 4 eram os leitos onde desenvolvemos este estudo.

Esses dados evidenciam que o principal dispositivo para a internação em saúde mental no contexto brasileiro e no Estado do Paraná ainda são os HP, em detrimento dos LSMHG e outras formas de internação em saúde mental. Apesar de forte incremento em outros pontos da RAPS, os LSMHG ainda são incipientes.

Diante disso, essa pesquisa se propôs a caracterizar as internações realizadas nos LSMHG implantados em um município da região centro-sul do Paraná, visando constituir um diagnóstico institucional. Segundo Baremblitt (2002), “[...] em diferentes

2 Revisão da Portaria GM/MS $n^{0} 3088 / 2011$, da RAPS , com a aprovação da Portaria $n^{0} 3588$, de 21 de dezembro de 2017, reafirmada pela NOTA TÉCNICA No 11/2019-CGMAD/DAPES/SAS/MS que se propõe a prestar esclarecimentos sobre as mudanças na Política Nacional de Saúde Mental e nas Diretrizes da Política Nacional sobre Drogas, publicada no dia 04 de fevereiro de 2019 (BRASIL, 2019). 
momentos da constituição de um campo de análise e/ou intervenção, os institucionalistas efetuam vários tipos de diagnósticos" (BAREMBLITT, 2002, p. 67). O diagnóstico, segundo esta perspectiva, tem um caráter sempre provisório e visa contribuir com a construção de um planejamento em relação a um determinado processo, revelando aspectos instituídos e forças instituintes.

\title{
Método
}

Este artigo é um recorte analítico de uma pesquisa mais ampla ${ }^{3}$, de abordagem quantiqualitativa com viés descritivo, sob a perspectiva da Análise Institucional (AI). Entretanto, é necessário pontuarmos que não compreendemos a abordagem quanti-qualitativa dentro de uma perspectiva dicotômica. Segundo Cesar, Silva e Bicalho (2013), esse tipo de pesquisa deve ser visto como dimensões de um processo e não sob a ótica dicotômica na qual tradicionalmente tem sido apreendidos pela ciência. Segundo os autores:

\begin{abstract}
Quando a questão do 'quali-quanti' é deslocada para além da dicotomia ou da integração, como planos de inseparabilidade de produção do real, desdobra-se também a possibilidade de retirada dos dispositivos de pesquisa de uma classificação apriorística, quantitativos ou qualitativos [...]. Ao contrário, os dispositivos, em vez de distribuídos em um ou outro método ou função, puramente uma coisa ou outra, portariam as duas dimensões, tanto uma face intensiva quanto extensiva, e isso não dividiria o dispositivo, ao contrário, abriria possibilidades de múltiplos usos, afirmando seu caráter de hibridismo. No dispositivo, portanto, intensivo-extensivo, força-forma, quanti-quali, comparecem como afirmação do caráter híbrido de constituição do real (CESAR; SILVA; BICALHO, 2013, p. 368-369).
\end{abstract}

O viés descritivo, segundo Gil (2008), é utilizado para a descrição de característica de uma população ou fenômeno. Nesta pesquisa, aplica-se o estudo de características dos processos de internação nos LSMHG.

A perspectiva da $\mathrm{AI}$, enquanto instrumental de compreensão e abordagem da realidade, propõe-se a interrogar a neutralidade, a objetividade e a totalização dos saberes, próprio das ciências tradicionais, inserindo a possibilidade de interação entre o saber acadêmico, dos experts e o conhecimento e saberes dos sujeitos individuais e coletivos envolvidos na pesquisa (AGUIAR; ROCHA, 2003).

Nesta primeira etapa da pesquisa o campo foi constituído pelos LSMHG, os quais tiveram sua implantação em 2014, em uma cidade da região centro-sul do Paraná, que de acordo

\footnotetext{
3 A pesquisa mais ampla está atrelada à dissertação de mestrado da primeira autora, sob orientação do segundo autor, tendo sido conformada em duas etapas, sendo a primeira delas (referente ao diagnóstico institucional) apresentada neste artigo e a segunda apresentada em outro artigo. Na segunda etapa da pesquisa os dados produzidos na primeira foram apresentados e colocados em discussão junto aos trabalhadores da rede de atenção psicossocial do município, através da realização de grupos focais de discussão.
} 
com o Instituto Brasileiro de Geografia e Estatística ([2019]) possui população estimada de 52 mil habitantes no ano de 2019.

A caracterização foi realizada através da análise de dois bancos de dados no período de março/2018 a junho/2018, disponibilizados pelo gestor do hospital após assinatura de termo de autorização. O primeiro constituído da consulta aos laudos do sistema de regulação estadual, disponibilizados pelo hospital desde a abertura desse serviço, em setembro de 2014, até o mês de dezembro de 2017, constituindo-se de 545 laudos analisados, nos quais consultamos os seguintes dados: local de moradia (urbano ou rural), faixa etária, sexo, procedimento solicitado, diagnóstico principal, tempo de permanência, outros procedimentos solicitados, local de encaminhamento, número de internamentos e reinternamentos.

O segundo banco de dados foi construído através das informações repassadas pelo setor de Serviço Social do Hospital, referentes à internação involuntária e números de transferências para outros serviços hospitalares.

A partir desses dois bancos de dados foram construídas tabelas, organizadas em quadros e gráficos, estes últimos construídos no Excel e apresentados nos resultados. Não ocorrendo perdas amostrais. Os dados produzidos são compreendidos como analisadores, os quais se constituem, para a análise institucional, por elementos que podem provocar e fazer surgir, com mais força, uma análise (LOURAU, 1993).

Esta pesquisa segue as diretrizes preconizadas pela Resolução n. 466/2012 e pela Resolução n. 510/2016, tendo sido aprovada pelo Comitê de Ética em Pesquisa (COMEP) da Universidade Estadual do Centro-Oeste (UNICENTRO), sob o Parecer n. 2.409.245, de o1/12/2017.

\section{Resultados}

Os LSMHG constituem-se como um dos pontos de atenção da RAPS desse município. A rede de saúde do município em estudo possui dez unidades de Estratégias de Saúde da Família (ESF), representando uma cobertura de 78,68\%, estimando-se cobertura populacional por ESF de 40.883 pessoas. O município conta com duas unidades básicas de saúde localizadas na área central para atender a população das áreas descobertas por ESF, com isso a estimativa de cobertura da Atenção Básica é de 98,66\%.

Fazem parte dessa rede dois hospitais gerais filantrópicos, que possuem contrato com o Estado para prestarem serviços hospitalares para o município, sendo que é em um desses hospitais que funcionam os LSMHG. Há ainda um CAPS I e um Centro de Atenção Psicossocial - Âlcool e Drogas (CAPS AD), referências para demandas de saúde mental no município. 
Os LSMHG estão em funcionamento desde setembro de 2014, em um hospital filantrópico, junto da enfermaria geral. São quatro leitos, que destinam-se a usuários adultos de ambos os sexos, maiores de idade, residentes e domiciliados nesse município.

Não há uma equipe específica para atendimento nos leitos, mas sim uma equipe referenciada para este fim, composta de um médico clínico geral, uma assistente social, enfermeiros(as) e técnicos(as) de enfermagem, que atendem também os demais internamentos hospitalares. Não há áreas de convivência específicas. Os usuários acompanhados dos familiares/acompanhantes podem circular na área externa do hospital para conversar, fumar e tomar chimarrão.

Em relação à caracterização dos usuários atendidos nesse serviço, destaca-se que, quanto ao local de moradia, conforme no Gráfico 1, a maioria dos usuários residem na zona urbana do município $(55 \%)$.

Gráfico 1 - Local de moradia dos usuários acolhidos nos LSMHG no período de set./2014 à dez./2017

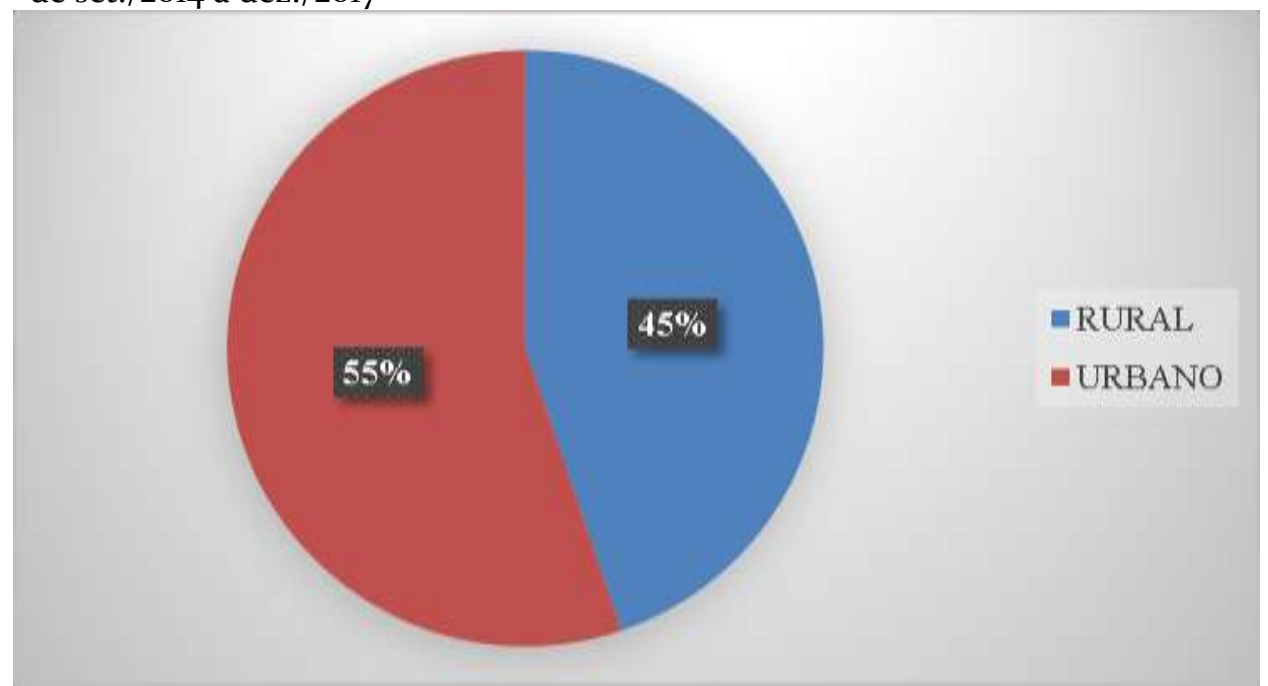

Fonte: Dados da pesquisa de campo, 2018.

Quanto à faixa etária dos usuários, constatou-se que 66\% encontram-se entre 19 à 49 anos, totalizando 359 usuários, conforme é possível observar no Gráfico 2. 
Gráfico 2 - Faixa etária dos usuários acolhidos nos LSMHG no período de set./2014 à dez./2017

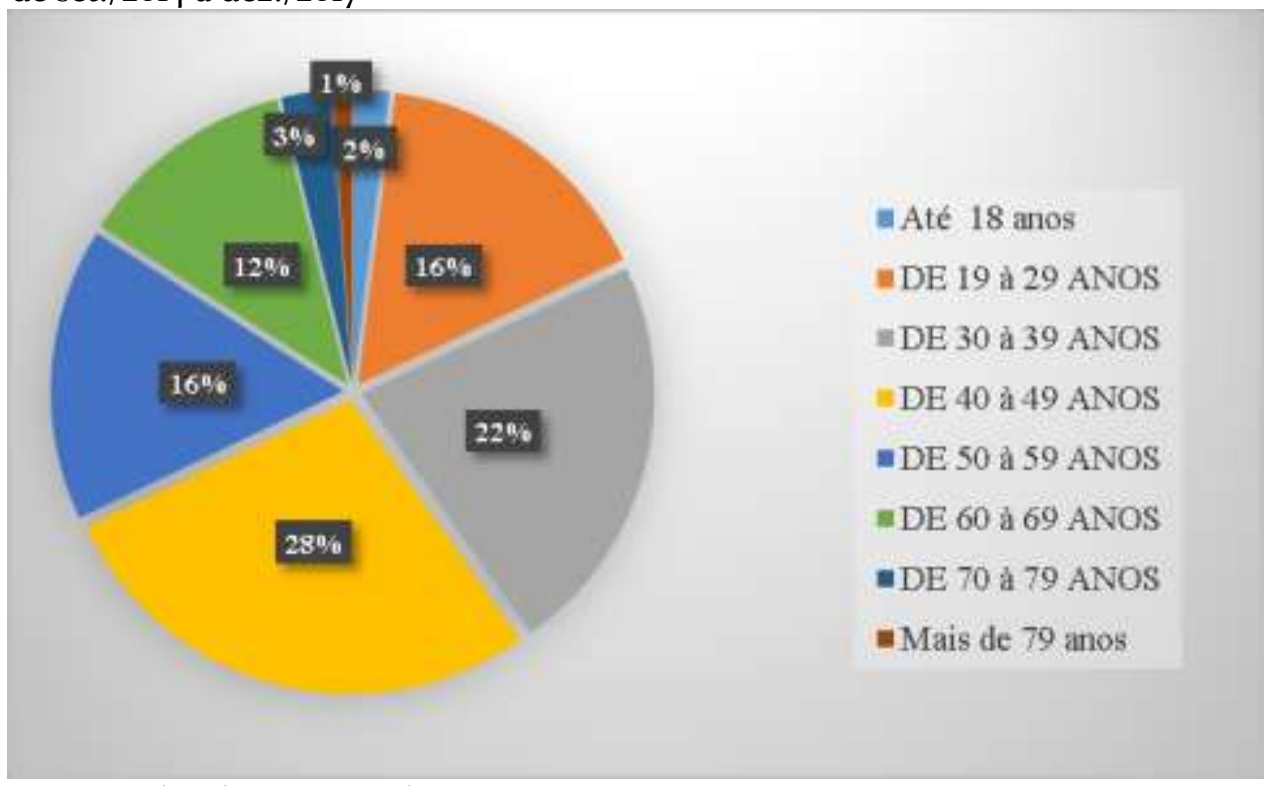

Fonte: Dados da pesquisa de campo, 2018.

Em relação ao total do público atendido, observa-se predominância de homens (64\%) em relação às mulheres (36\%), de acordo com o Gráfico 3.

Gráfico 3 - Distribuição por sexo dos usuários acolhidos nos LSMHG no período de set./2014 à dez./2017.

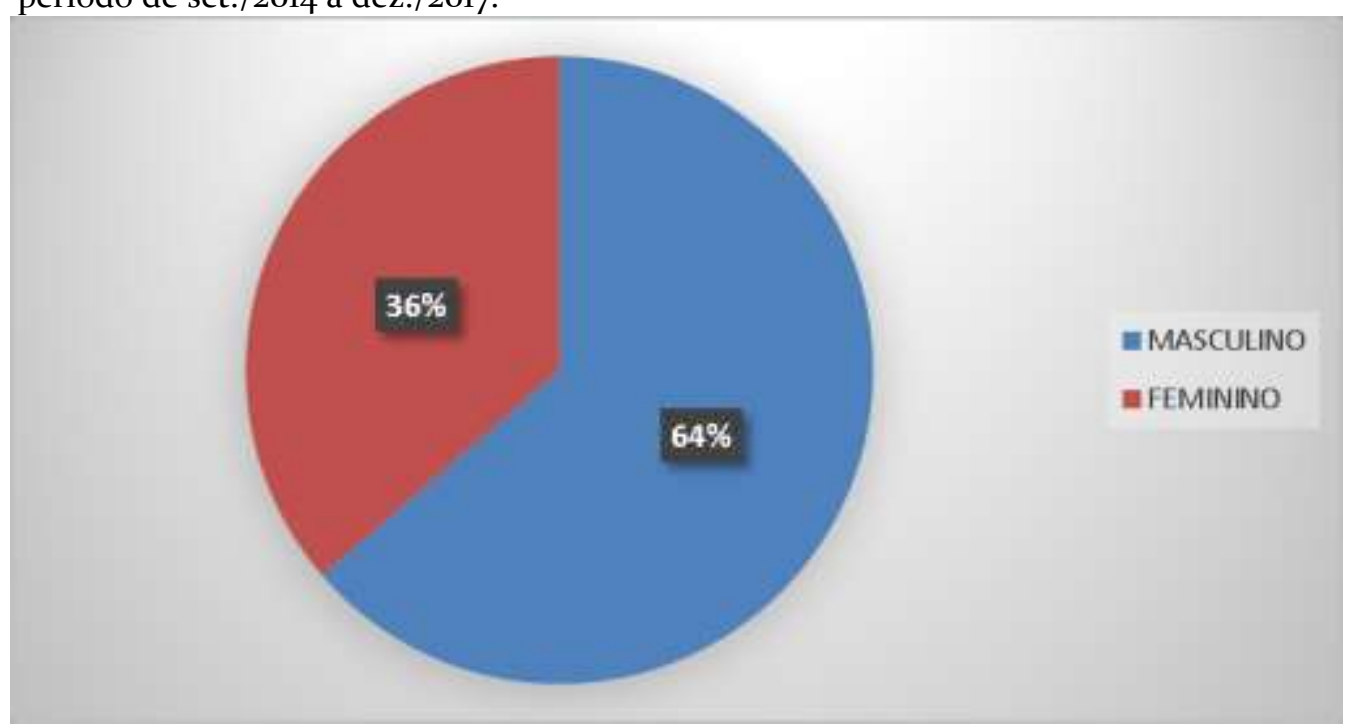

Fonte: Dados da pesquisa de campo, 2018.

Observa-se que $47,9 \%$ das internações ocorreram devido a problemas relacionados ao uso de substâncias psicoativas, 44,8\% devido a Esquizofrenia, transtornos esquizotípicos, transtornos delirantes e $4,6 \%$ a transtornos do humor (afetivos), conforme demonstra a Tabela 1. 
Tabela 1 - Hipótese Diagnóstica das internações realizadas nos LSMHG no período de set./2014 à dez./2017.

\begin{tabular}{lcc}
\hline HIPÓTESE DIAGNÓSTICA & QUANTIDADE & № RELATIVO \\
\hline F10 - F19 & 261 & 47,9 \\
F20 - F29 & 244 & 44,8 \\
F30 - F39 & 25 & 4,6 \\
Outros & 15 & 2,7 \\
\hline TOTAL & 545 & 100 \\
\hline
\end{tabular}

Fonte: Dados de pesquisa de campo, 2018.

No Gráfico 4 apresenta-se que, do total de internamentos relacionados ao comportamento (F20-F29 e F30-F39), 59\% são do sexo feminino e 41\% do sexo masculino. Quanto aos internamentos relacionados à substância ( $\left.\mathrm{F}_{10}-\mathrm{F}_{19}\right)$, 11\% são do sexo feminino e 89\% são do sexo masculino.

Gráfico 4 - Hipótese diagnóstica por sexo dos usuários acolhidos nos LSMHG no período de set./2014 à dez./2017

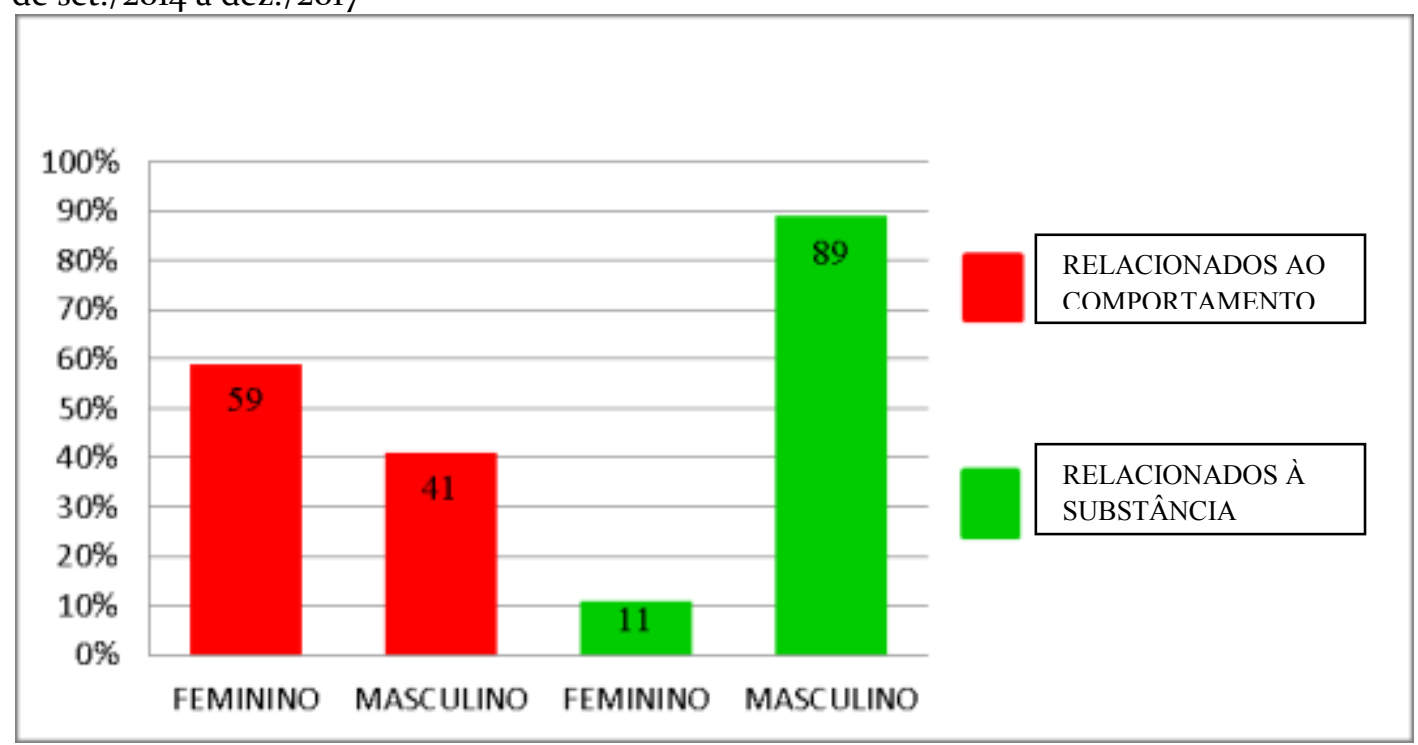

Fonte: Dados da pesquisa de campo, 2018.

A partir dos resultados apresentados no Gráfico 5 é possível observar que $82 \%$ dos usuários atendidos nos Leitos ficaram em acolhimento por curto tempo de permanência, até 7 dias.

4 De acordo com a Classificação Internacional de Doenças e Problemas Relacionados à Saúde (CID - 10): F10 - F19: transtornos mentais e comportamentais devidos ao uso de substância psicoativa; F20-F29: Esquizofrenia, transtornos esquizotípicos e transtornos delirantes; F30-F39: Transtornos do humor (afetivos). 
Gráfico 5 - Tempo de Permanência dos usuários acolhidos nos LSMHG no período de set./2014 à dez./2017

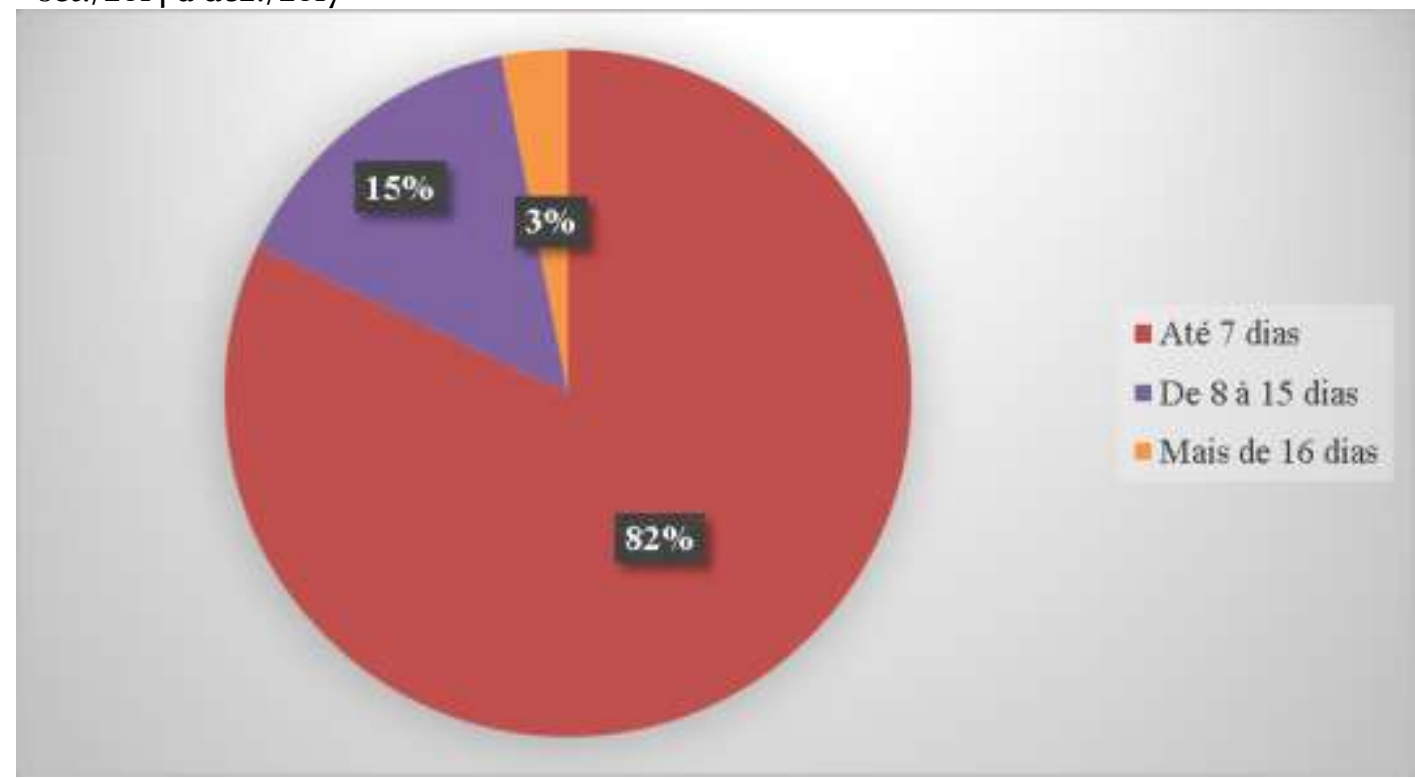

Fonte: Dados da pesquisa de campo, 2018.

Em relação à origem dos encaminhamentos, conforme apresenta-se na Tabela 2, foi possível verificar que $64,9 \%$ dos encaminhamentos para os LSMHG foram realizados pelo Pronto Atendimento Municipal, sendo que 33,8\% dos encaminhamentos constavam como não informados. Importante mencionar que não há no Município uma Central de Regulação.

Tabela 2 - Origem dos encaminhamentos para os LSMHG no período de set./2014 à dez./2017

\begin{tabular}{lcc}
\multicolumn{1}{c}{ ORIGEM DO } & QUANTIDADE & № RELATIVO \\
\hline Pronto Atendimento Municipal & 353 & 64,9 \\
CAPS AD & O4 & 0,7 \\
Hospital Geral Municipal & 02 & 0,4 \\
Hospital Geral Regional & 01 & 0,2 \\
Sem informações & 184 & 33,8 \\
\hline TOTAL & $\mathbf{5 4 5}$ & $\mathbf{1 0 0 \%}$ \\
\hline
\end{tabular}

Fonte: Dados da pesquisa de campo, 2018.

Quanto aos dados de internamentos involuntários, conforme Gráfico 6, no ano de 2017 foram atendidos de forma involuntária 9\% dos 203 internamentos realizados nesse ano, totalizando 18 usuários. 
Gráfico 6 - Internamentos Involuntários realizados no ano de 2017 nos LSMHG

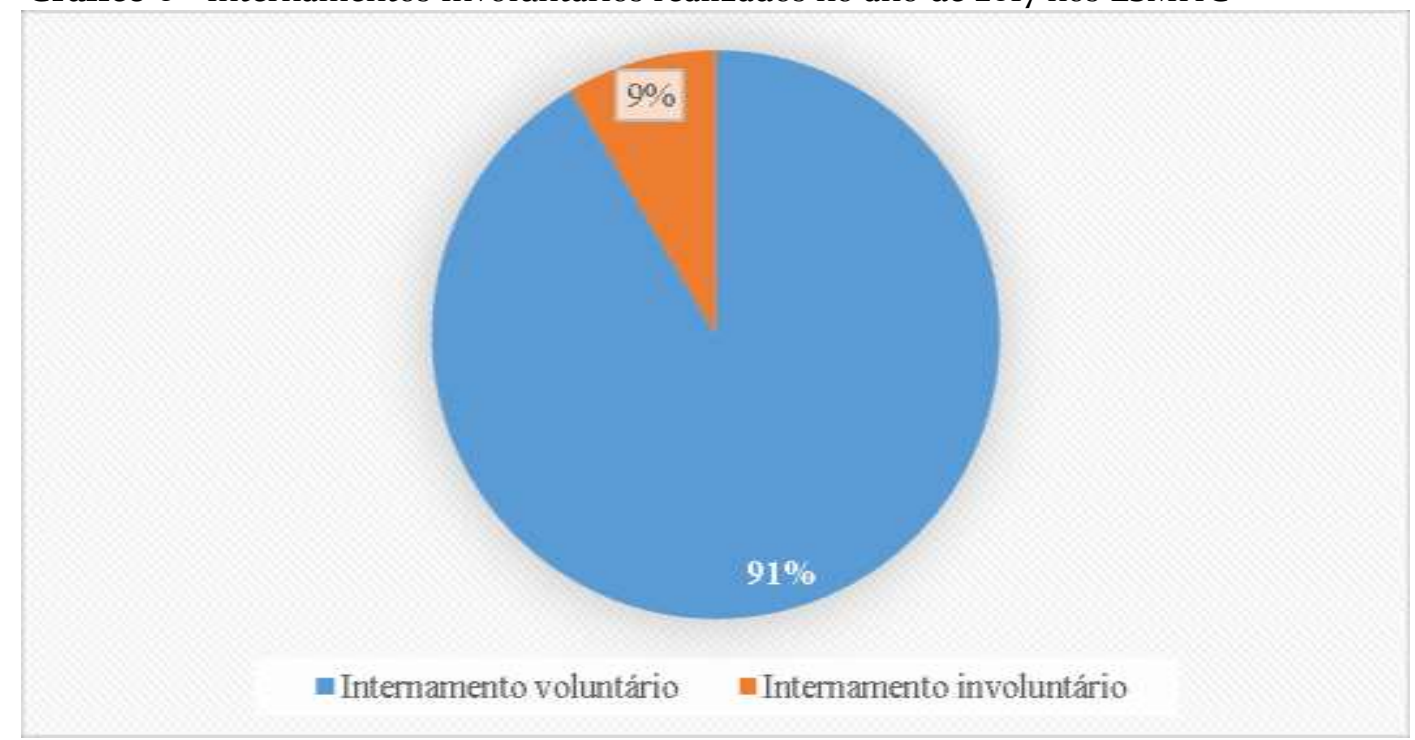

Fonte: Dados da pesquisa de campo, 2018.

Analisando a Tabela 3 observa-se um progressivo aumento anual no número de usuários internados.

Tabela 3 - Internamentos por ano de usuários nos LSMHG de set./2014 à dez./2017

\begin{tabular}{lcc}
\hline \multicolumn{1}{c}{ ANO } & QUANTIDADE & № RELATIVO \\
\hline 2014 & 33 & 6,0 \\
2015 & 150 & 27,5 \\
2016 & 159 & 29,2 \\
2017 & 203 & 37,3 \\
\hline TOTAL & $\mathbf{5 4 5}$ & $\mathbf{1 0 0} \%$ \\
\hline
\end{tabular}

Fonte: Dados da pesquisa de campo, 2018.

Por sua vez, a Tabela 4 demonstra que ocorreram no período analisado, 123 reinternamentos do total de 545, representando $22,5 \%$ do total de internamentos no período.

Tabela 4 - Reinternamentos de usuários nos LSMHG de set./2014 a dez./2017.

\begin{tabular}{lc}
\hline \multicolumn{1}{c}{ TOTAL DE USUÁRIOS } & № DE REINTERNAMENTOS \\
\hline O1 USUÁRIA & 15 \\
o1 USUÂRIA & 07 \\
o2 USUÁRIAS & 05 \\
o1 USUÁRIA & 04 \\
o7 USUÁRIOS & 03 \\
15 USUÁRIOS & 02 \\
36 USUẤRIOS & 01 \\
\hline 63 USUÁRIOS & $\mathbf{1 2 3}$ \\
\hline
\end{tabular}

Fonte: Dados da pesquisa de campo, 2018.

Argum., Vitória, v. 12, n. 2, p. 141-164, maio/ago. 2020. | ISSN 2176-9575 
Outro dado que pode ser destacado é o número de usuários que são transferidos para outros serviços hospitalares, entre os quais estão incluídos hospitais psiquiátricos e alas psiquiátricas em hospitais gerais. Dos 545 usuários internados durante o período analisado, 16 (3\%) foram encaminhados para outros serviços. Esse resultado pode ser observado no Gráfico 7.

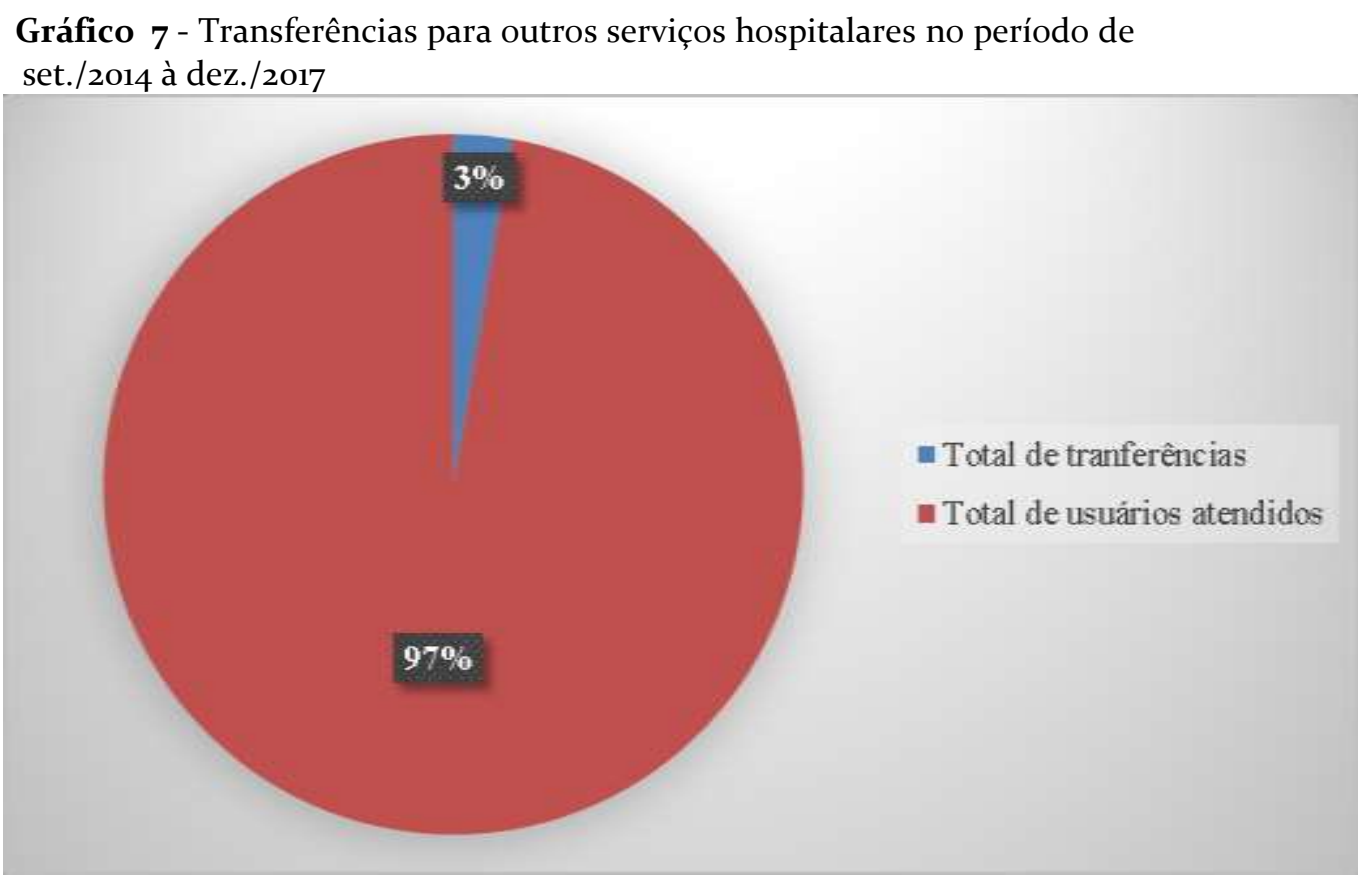

Fonte: Dados da pesquisa de campo, 2018.

Em relação aos outros procedimentos solicitados aos usuários, foram registradas as solicitações de 1098 exames, sendo os mais frequentes o hemograma completo (210), a dosagem de creatinina (198), dosagem de glicose (192) e dosagem de ureia (180). Há ainda o registro de outros 31 exames, com frequência de o1 até 50.

\section{Discussão}

Em relação à caracterização do público atendido, observa-se predominância de homens (64\%) em relação às mulheres $(36 \%)$ do total de atendimentos nos LSMHG no período analisado. Esse resultado é consonante a pesquisa realizada em LSMHG de referência da $4^{\text {a }}$ Coordenadoria Regional de Saúde do Estado do Rio Grande do Sul, durante o ano de 2016, na qual verificou-se que a maioria (68\%) das internações eram do sexo masculino (CARVALHO et al., 2019).

Segundo Gomes, Nascimento e Araújo (2007), esses dados contrastam com os estudos que indicam menor presença de homens em serviços de atenção primária, assim como Campos, Ramalho e Zanello (2017) e Paiva et al. (2019), que indicam menor presença de homens em serviços de atenção psicossocial. 
Segundo Gomes, Nascimento e Araújo (2007), a menor presença de homens em serviços de saúde ocorre a despeito da indicação de que eles "[...] padecem mais de condições severas e crônicas de saúde do que as mulheres e também morrem mais do que elas pelas principais causas de morte" (GOMES; NASCIMENTO; ARAÚJO, 2007, p. 565). Segundo os autores, ainda é possível citar como motivos que levam os homens a procurarem menos os serviços de saúde estão relacionados a aspectos culturais e simbólicos, como a percepção de cuidado ligado a figuras femininas, assim como por condições relacionadas ao trabalho e ao mundo produtivo.

Apesar da menor presença de homens em serviços de atenção primária e secundária, os LSMHG apresentam uma maior proporção deles, levando-nos a refletir sobre a possibilidade de que é nos momentos de crise e intensificação do sofrimento que os homens se inserem no sistema de saúde, via internação. Pode-se compreender, assim, que o sofrimento psíquico é gendrado (ZANELLO; FIUZA; COSTA, 2015), ou seja, se expressa de modo diferente conforme o gênero, podendo desdobrar-se em diferentes formas de acesso a serviços de saúde.

Quando se faz o cruzamento entre os dados de sexo e hipótese diagnóstica, percebe-se que há maior proporção de mulheres internadas por transtornos relacionados ao comportamento e maior proporção de homens internados por transtornos relacionados ao uso de substâncias. Esses dados assemelham-se aos achados da pesquisa de Silva et al. (2014), realizada no Estado do Paraná sobre o perfil de internações hospitalares em unidade psiquiátrica de um hospital geral, que demonstrou que a maioria que buscou internação devido ao uso de substâncias psicoativas também eram homens (65,4\%). Enquanto que entre as mulheres $79,8 \%$ tiveram problemas relacionados ao comportamento. Esse estudo analisa que esta característica das mulheres buscarem menos os serviços devido ao uso de substância, pode estar relacionada ao estigma social que enfrentam, podendo esconder a dependência por mais tempo (SILVA et al., 2014).

Nota-se proveniência ligeiramente maior do meio urbano do que do meio rural. Ao recorrer à distribuição populacional do município, conforme o último Censo do IBGE do ano de 2010 , percebe-se que $54 \%$ da população concentra-se no interior e que $46 \%$ estão na zona urbana. Esse município está entre os cinco maiores do Estado do Paraná em extensão territorial, fato que se torna relevante na organização dos atendimentos das diversas políticas públicas no município e que pode se tornar fator de dificuldade para o acesso da população do campo aos serviços que são mais centralizados.

Quanto à faixa etária dos usuários, constatou-se que 66\% encontram-se entre 19 à 49 anos de idade. Dados semelhantes foram encontrados na pesquisa de Carvalho et al. (2019), apresentando prevalência de $63 \%$ de usuários entre 19 a 59 anos. Diante desse dado, observou-se que a maioria dos usuários que foram acolhidos nos LSMHG no período analisado, encontravam-se na fase produtiva, tendo como base a legislação trabalhista e o mercado de trabalho brasileiro. Na pesquisa de Wadi, Olinto e Casagrande (2015), 
confirma-se esse fenômeno do aumento do número de jovens e adultos ocupando os leitos.

Ao analisar o tempo de permanência dos usuários nos LSMHG, é possível inferir que esse serviço vem buscando responder ao que está estabelecido no inciso I do art. $3^{\circ}$ da Portaria n. 148/2012, que refere que as internações devem ser de curta duração, até a estabilidade de cada caso, pois o índice maior foi de até 7 dias de internação representado por $82 \%$ das internações realizadas, enquanto que em outras pesquisas semelhantes prevaleceu o tempo de 16 a 30 dias, o que representou 54\% das internações (SILVA et al., 2014; CARVALHO et al., 2019).

O curto de tempo de internação é consonante com a proposta da RPB, que consiste na superação de aspectos manicomiais, como as longas internações em territórios distantes dos locais de moradia dos usuários. As internações de longo prazo estão associadas a maiores possibilidades de cronificação, estigmatização e desvinculação comunitária e familiar (PAES et al., 2013).

A rede na qual os LSMHG estão inseridos possui CAPS I e CAPS AD, além de cobertura da ESF de 78,68\%, conforme dados do sistema e-Gestor Atenção Básica (2019), apresentando, assim, certo grau de articulação, que podem possibilitar trocas e corresponsabilização no cuidado extra-hospitalar. É possível inferir que a constituição de uma rede de atenção psicossocial fortalecida possibilita períodos mais curtos de internação, pois os usuários tem outras opções assistenciais como referência para o cuidado.

A maioria dos encaminhamentos para os leitos foram realizados via Pronto Atendimento Municipal $(64,9 \%)$, não foi possível levantar, através das fontes analisadas, a origem dos encaminhamentos, se foi busca direta do usuário ou se foi encaminhada por outro serviço público de saúde. Na pesquisa de Silva et al. (2014), cerca de 40,8\% dos encaminhamentos foram realizados por serviços públicos de saúde.

De acordo com Dias, Gonçalves e Delgado (2010), deve funcionar no município um Sistema de Regulação de Vagas, que evitariam, entre outras dissimulações do serviço, as internações de porta, ou seja através de Prontos Atendimentos.

A modalidade de internamento também se constitui como importante analisador, na medida em que revela aspectos relacionados aos modelos de atenção e as articulações intersetoriais.

Quanto à modalidade de internamento, a Lei 10.216/2001 (BRASIL, 2001) define três: voluntária, involuntária e compulsória, verificou-se que a primeira se destina àqueles usuários que concordam com a oferta desse tipo de tratamento, enquanto a segunda refere-se àquelas que são requeridas por familiares e/ou terceiros, independente da vontade do usuário. A terceira modalidade, a internação compulsória, é aquela realizada por determinação judicial. No ano de 2017 foram atendidos de forma involuntária 18 
usuários (9\%) do total de 203 internamentos realizados. Portanto, constata-se que a internação voluntária apresentou maior percentual, com 91\% das internações.

Dados da pesquisa de Carvalho et al. (2019) demonstram que a internação voluntária também apresentou maior percentual naquele cenário, com $76 \%$ das internações, enquanto a compulsória apresentou $23 \%$ e a involuntária representou $1 \%$. Quanto às internações compulsórias, observou-se um contraste entre a pesquisa de Carvalho et al. (2019) e os resultados encontrados nesta pesquisa.

No município em estudo não houve, no período analisado, nenhuma internação compulsória, o que está relacionado à articulação entre o Ministério Público (MP) e os LSMHG, visando diminuir a judicialização da saúde mental. Quando surge no MP alguma demanda por internamento compulsório, a equipe realiza contato com os profissionais dos LSMHG e esses articulam com os demais serviços da rede para proceder a avaliação da demanda, sem necessariamente abrir um processo judicial, caracterizando-se como estratégia extrajudicial, a juridicização. Esta, ao contrário da judicialização, é compreendida como "[...] a ideia de consenso pelo diálogo, ou seja, a ênfase num processo de negociação, pactuação e concessão recíproca entre os diversos atores cujo resultado é construído consensualmente" (MUSSE; PESSOA; SOUZA, 2019, p. 21).

Em relação ao aumento do número de internações por ano, esse dado pode estar relacionado à integração e ao reconhecimento desse serviço na rede, bem como à diminuição de internamentos fora do município. Por outro lado, poderia também indicar uma possível (des)potencialização dessa rede (DIAS; GONÇALVES; DELGADO, 2010), devendo ser um aspecto analisado junto às equipes de saúde.

Outro importante analisador do funcionamento da RAPS é o índice de reinternamentos. Os dados evidenciam que houve reinternação em $22 \%$ dos casos, índice inferior aos 36,5\% apresentados no estudo de Zanardo et al. (2017) em um HG de Porto Alegre, e ainda mais distante da porcentagem de reinternamentos no HP Dr. João Machado em Natal (RN) verificada por Bezerra e Dimenstein (2011), que foi maior que 60,3\%.

Esse índice de reinternamento pode ser considerado um indicador de efetividade de uma rede integrada em funcionamento. Porém, mesmo sendo um número inferior aos estudos analisados, pode evidenciar que embora os usuários não estejam mais sob a égide da internação de longa permanência, acabam sendo submetidos a recorrentes internações de duração breve. Esse fato pode ser remetido ao fenômeno denominado na literatura em língua inglesa pela expressão revolving door a qual refere-se a porta giratória, fato que ocorria com frequência nos hospitais psiquiátricos indicando as reincidências dos usuários nos hospitais (BEZERRA; DIMENSTEIN, 2011), com possível evolução para uma outra configuração de institucionalização, os novos crônicos (MACHADO; SANTOS, 2013).

Os reinternamentos podem apontar para a falta ou insuficiência de serviços substitutivos e comunitários, como também para a dificuldade de aderência a esses serviços pelos 
usuários, entre outros fatores de ordem singular do cotidiano, como ausência de vínculos familiares e comunitários (BEZERRA; DIMENSTEIN, 2011; ZANARDO et al., 2017).

Portanto, a presença de um grande número de reinternações poderia indicar a existência de poucos dispositivos comunitários ou de que esses não estão articulados ao hospital, fazendo com que os usuários sejam alvo de atenção apenas nas situações de crise e no dispositivo hospitalar, sem acompanhamento pós-alta. O que não parece ser o que esta pesquisa está evidenciando sobre a rede em estudo. Além do índice de reinternação ser baixo, a maioria dos usuários apresenta 1 ou 2 reinternamentos, sendo que apenas 12 usuários apresentam 3 ou mais.

Os dados apresentados também evidenciam que é pouco frequente a transferência de pacientes para outros serviços, como para o CAPS AD III, para hospitais psiquiátricos, para leitos em unidades psiquiátricas ou para hospitais com mais recursos para atendimento clínico. Em todos esses casos, tais serviços são localizados fora do município onde o estudo foi realizado, demandando deslocamento. Observou-se uma taxa de somente $3 \%$ de transferências.

A presença dos leitos neste território propicia a diminuição do número de internamentos fora do município, como resultado de uma ação de resistência das equipes de saúde mental, e isso vem a facilitar o acompanhamento e a aproximação dos usuários pelos familiares no território. Por outro lado, se mesmo havendo o LSMHG, alguns casos são transferidos para enfermarias psiquiátricas ou HP, pode-se deduzir que o HG ocupou um papel complementar, mas não substitutivo, sendo necessário tensionar tais práticas.

Ainda há uma insistência da sociedade para a exclusão das pessoas em sofrimento psíquico, evidenciando que a internação tem funções híbridas: de cuidados em saúde; de proteção/assistência ao sujeito; de proteção da sociedade e exclusão (DESVIAT, 2015). As forças relacionadas à cultura hospitalocêntrica muitas vezes segue operando na sociedade, que ainda associa a pessoa em sofrimento psíquico a periculosidade, prescrevendo a essa a reclusão e o isolamento do convívio social. Diante disso, é função das equipes de saúde fazer o enfrentamento a tais concepções, ofertando possibilidades substitutivas de cuidado.

A solicitação de outros procedimentos para os usuários vai ao encontro com a especificidade da clínica médica, própria dos hospitais gerais e da política de atenção psicossocial, que visa o atendimento integral do sujeito, respeitando sua singularidade e complexidade.

Conforme Cecílio e Merhy (2003), a atenção integral de um usuário, que por certo período de sua vida, precisa de cuidados hospitalares, se dá via uma abordagem completa, holística, visando garantir desde o consumo de todas as tecnologias de saúde existentes para manter, melhorar e prolongar a vida, até a organização de um espaço confortável e seguro para a pessoa hospitalizada. 


\section{Considerações finais}

Elenca-se como processos instituintes que colaboram para o modo-psicossocial de atenção em saúde mental alguns pontos característicos desse serviço. Entre eles, destaca-se que a presença dos LSMHG favorece a proximidade com os demais pontos da rede e com o território de vida dos usuários, bem como o tempo curto de permanência nos leitos, o que contrasta com o imaginário social de longas internações, assim como com as novas diretrizes políticas, que tem preconizado a inserção dos HP na RAPS e maior taxa de ocupação e tempo de uso dos leitos. Além disso, os LSMHG proporcionam aos usuários avaliação das questões clínicas, pensado no sujeito em sua totalidade.

O baixo índice de transferências para outros serviços indica a potência deste dispositivo na RAPS e na possibilidade de efetivação de uma rede de cuidados territoriais, em consonância com os princípios da RPB e da atenção psicossocial.

Apesar de ser baixo o número de transferências, ainda assim torna-se interessante a realização de novos estudos para compreender o que as motivaram. Do mesmo modo, apesar do índice de reinternações não ser considerado elevado em comparação com outras pesquisas, é pertinente a realização de pesquisas que possam ampliar a compreensão de seus determinantes, como os itinerários que conduzem os usuários a elas, os sentidos da internação para esses usuários, a relação desses usuários com a RAPS, quais são as hipóteses diagnósticas desses reinternamentos, entre outras questões.

Entre as limitações para realização deste estudo encontraram-se questões institucionais relacionadas ao acesso aos prontuários, limitando o acesso aos laudos que são encaminhados para o sistema de informações da Secretaria de Estado da Saúde e dados de atendimento do setor de serviço social do hospital, os quais são formatados para a comprovação dos atendimentos e para o recebimento de recursos.

Portanto, há necessidade de pesquisas que busquem informações sobre o motivo da alta, articulação entre os serviços da RAPS durante e posteriormente ao internamento, a relação com familiares no processo de internação, como também a investigação da origem dos encaminhamentos ao Pronto Atendimento Municipal, que caracterizou-se como o maior encaminhador para os LSMHG.

É importante ressaltar que este artigo efetuou um recorte analítico da primeira etapa de uma pesquisa mais ampla, sendo que a segunda etapa, apresentada em outro artigo, propiciou o desenvolvimento de grupos de discussão com as equipes de atenção psicossocial do município. Este recorte possibilitou importante conhecimento sobre o processo de internação nos LSMHG desse município, que pode contribuir para o planejamento de ações da gestão municipal nessa área, como melhoria da assistência ao usuário e ao trabalho da RAPS, além de produzir conhecimento científico sobre a temática e servir como referência para novos estudos, principalmente nesse momento em que 
enfrenta-se mais desafios, principalmente com a aprovação de novas legislações que favorecem um retrocesso no movimento reformista.

Percebe-se que os LSMHG, exercem efeito instituinte sobre as formas consolidadas de atendimento à pessoa em sofrimento psíquico, ou seja, seguem rompendo com os processos instituídos, num constate processo de transformação, característicos da RPB, que não limita-se apenas à implantação de serviços, mas sobretudo a mudanças de paradigmas em saúde mental.

\section{Referências}

AGUIAR, Katia Faria de; ROCHA, Marisa Lopes da. Pesquisa-intervenção e a produção de novas análises. Psicologia: ciência e profissão, Brasília (DF), v. 23, n. 4, p. 64-73, 2003.

AMARANTE, P. Saúde Mental e Atenção Psicossocial. 4.ed., Rio de Janeiro: Editora Fiocruz, 2007.

BAREMBLITT, G. Compêndio de análise institucional e outras correntes: teoria e prática. 5.ed. Belo Horizonte: Instituto Felix Guattari (Biblioteca Instituto Félix Guattari), 2002.

BEZERRA, Cíntia Guedes; DIMENSTEIN, Magda. O fenômeno da reinternação: um desafio à Reforma Psiquiátrica. Mental, Barbacena, v. 9, n. 16, p. 417-441, 2011.

BOTEGA, N. J. Psiquiatria no hospital geral: histórico e tendência. In: BOTEGA, N.J (org.). Prática psiquiátrica no hospital geral: interconsulta e emergência. 4. ed. Porto Alegre: Artmed, 2017.

BRASIL. Lei no 10.216/20o1, de 6 de abril de 20o1.Dispõe sobre a proteção e os direitos das pessoas portadoras de transtornos mentais e redireciona o modelo assistencial em saúde mental. Brasília (DF), 2001. Disponível em:

http://www.planalto.gov.br/ccivil 03/Leis/LEIS 2001/L10216.htm. Acesso em: jun. 2018.

BRASIL. Ministério da Saúde. Nota Técnica no 11/2019-CGMAD/DAPES/SAS/MS.

Brasília (DF), 2019. Disponível em: http://pbpd.org.br/wp-

content/uploads/2019/02/o656ad6e.pdf.Acesso em: jan. 2019.

BRASIL. Ministério da Saúde. Portaria GM no 3.588, de 21 de dezembro de 2017. Altera as Portarias de Consolidação no 3 e no 6, de 28 de setembro de 2017, para dispor sobre a RAPS, e dá outras providências. Brasília (DF), 2017. Disponível em:

http://bvsms.saude.gov.br/bvs/saudelegis/gm/2017/prt3588_22_12_2017.html. Acesso em: maio. 2018. 
BRASIL. Ministério da Saúde. Saúde Mental em Dados 12, Brasília (DF), ano 10, n. 12, out. 2015. Informativo eletrônico. Disponível em:

http://portalarquivos.saude.gov.br/images/pdf/2015/outubro/20/12-edicao-do-SaudeMental-em-Dados.pdf. Acesso em ago. 2017.

BRASIL. Ministério da Saúde. Portaria GM no 148 de 31 de janeiro de 2012. Estabelece as normas de funcionamento e habilitação do Serviço Hospitalar de Referência para atenção a pessoas com sofrimento ou transtorno mental e com necessidades de saúde decorrentes do uso de álcool, crack e outras drogas, do Componente Hospitalar da RAPS, e institui incentivos financeiros de investimento e de custeio. Diário Oficial da União, Brasília (DF), 2012a. Disponível em:

http://portalarquivos2.saude.gov.br/images/pdf/2015/marco/10/PORTARIA-148-31JANEIRO-2012.pdf. Acesso em: 3 jun. 2017.

BRASIL. Ministério da Saúde. Portaria GM no 349 de 29 de fevereiro de 2012 , que altera e acresce dispositivo à Portaria n 148/2012. Brasília (DF), 2012b. Disponível em:

http://bvsms.saude.gov.br/bvs/saudelegis/gm/2012/prto349_29_02_2012.html. Acesso em: 10 ago. 2018.

BRASIL. Ministério da Saúde. Nota Técnica n $^{\circ}$ 25/2012, de 05 de junho de 2012 . Brasília (DF), 2012c. Disponível em:

http://portal.anvisa.gov.br/documents/33836/349757/Nota+t\%C3\%Agcnica+n\%C2\%BA+o 5+de+2012/3ab22be2-8212-4dga-9of2-e8efe7e62bfd. Acesso em: 10 ago 2018.

BRASIL. Ministério da Saúde. Portaria GM no 1.615, de 26 de julho de 2012. Altera o item II do artigo $9^{\circ}$ e os artigos $12^{\circ}$ e $13^{\circ}$ da Portaria $n^{\circ}$ 148/GM/MS, de 31 de janeiro de 2012. Brasília (DF), 2012d. Disponível em:

http://bvsms.saude.gov.br/bvs/saudelegis/gm/2012/prt1615_26_o7_2012.html. Acesso em: 8 jan. 2018.

BRASIL. Ministério da Saúde. Portaria GM 3088, de 23 de dezembro de 2011.Institui a RAPS para pessoas com sofrimento ou transtorno mental e com necessidades decorrentes do uso de crack, álcool e outras drogas, no âmbito do SUS. Disponível em:

http://bvsms.saude.gov.br/bvs/saudelegis/gm/2011/prt3088_23_12_2011_rep.html. Acesso em: 18 jun. 2017.

BRASIL. Ministério da Saúde. Portaria no 2.644, de 28 de outubro de 2009. Estabelece novo reagrupamento de classes para os hospitais psiquiátricos, reajusta os respectivos incrementos e cria incentivo para internação de curta duração nos hospitais psiquiátricos e dá outras providências. Disponível em:

http://bvsms.saude.gov.br/bvs/saudelegis/gm/2009/prt2644_28_10_20o9.html. Acesso em: 9 jun. 2020. 
BRASIL. Ministério da Saúde. Portaria no 52, de 20 de janeiro de 20o4. Institui o Programa Anual de Reestruturação da Assistência Psiquiátrica Hospitalar no SUS. Disponível em:

http://bvsms.saude.gov.br/bvs/saudelegis/gm/2004/prtoo52_20_01_2004.html. Acesso em: 9 jun. 2020.

BRASIL. Ministério da Saúde. Portaria GM no 251, de 31 de janeiro de 2oo2. Estabelece diretrizes e normas para a assistência hospitalar em psiquiatria, reclassifica os hospitais psiquiátricos, define e estrutura, a porta de entrada para as internações psiquiátricas na rede do SUS e dá outras providências. Brasília (DF), 2002a. Disponível em:

http://www.saude.gov.br/images/pdf/2015/marco/10/PORTARIA-251-31-JANEIRO2002.pdf. Acesso em: 9 jun. 2020.

BRASIL. Ministério da Saúde. Portaria GM n. 336, de 19 de fevereiro de 2002. Estabelece tipo de CAPS. Brasília (DF), 2002b. Disponível em: https://bvsms.saude.gov.br/bvs/saudelegis/gm/2002/prto336_19_02_2002.html. Acesso em: 10 jun. 2020.

BRASIL. Ministério da Saúde. Portaria SAS n 224, de 29 de janeiro de 1992 . Estabelece diretrizes e normas para a área de saúde mental. Brasília (DF), 1992. Disponível em: http://www.saude.mg.gov.br/images/documentos/Portaria_224.pdf. Acesso em: 18 jun. 2018.

CADASTRO NACIONAL DE ESTABELECIMENTOS DE SAÚDE. Disponível em: http://cnes2.datasus.gov.br/Mod Ind Tipo Leito.asp?VEstado=41. Acesso em: 5 jul. 2019.

CAMPOS, Ioneide de Oliveira; RAMALHO, Walter Massa; ZANELLO, Valeska. Saúde mental e gênero: $O$ perfil sociodemográfico de pacientes em um centro de atenção psicossocial. Estudos de Psicologia, Natal, v. 22, n. 1, p. 68-77, 2017.

CARVALHO, K. L.; TERRA, M. G.; MORESCHI, C.; SIQUEIRA, D. F.; MELLO, A. L; GAMEMANN, A. Características de internações em saúde mental de hospitais gerais do Rio Grande do Sul. REME-Rev Min Enferm., Belo Horizonte, n. 23, v. e-1203, jan. 2019.

CÉSAR, Janaína Mariano; SILVA, Fabio Hebert da; BICALHO, Pedro Paulo Gastalho de. O lugar do quantitativo na pesquisa cartográfica. Fractal: revista de psicologia, Niterói, v. 25, n. 2, p. 357-372, 2013.

CECILIO, L. C. O., MERHY, E. E. A integralidade do Cuidado como eixo da gestão hospitalar. Campinas, mar. 2003. Disponível em: http://www.hmdcc.com.br/wp-content/uploads/2018/o4/Cecilio-A-INTEGRALIDADEDO-CUIDADO-COMO-EIXO-DA-GEST\%C $3 \% 83$ O-HOSPITALAR.pdf. Acesso em: 5 jul. 2019. 
CLASSIFICAÇÃO INTERNACIONAL DE DOENÇAS - CID-10. Disponível em: BULAS. MED https://www.bulas.med.br/cid-10/. Acesso em: 10 jul.2019.

DESVIAT, M. A Reforma Psiquiátrica. 2. ed. Rio de Janeiro: Editora Fiocruz, 2015.

DIAS, M. K.; GONÇALVES, R. W; DELGADO, P. G. Leitos de Atenção Integral à saúde mental em hospital geral: configuração atual e novos desafios na política de saúde mental. In: VASCONCELOS, E. M (Org.). Desafios políticos da reforma psiquiátrica brasileira. São Paulo: Hucitec, 2010.

INSTITUTO BRASILEIRO DE GEOGRAFIA E ESTATÍSTICA (IBGE). Prudentópolis. Brasília (DF), [2019]. Disponível em: https://cidades.ibge.gov.br/brasil/pr/prudentopolis/panorama. Acesso em: 10 ago. 2019.

GIL, A. C. Como elaborar projetos de pesquisa. São Paulo: Atlas, 2008.

GOMES, Romeu; NASCIMENTO, Elaine Ferreira do; ARAÚJO, Fábio Carvalho de. Por que os homens buscam menos os serviços de saúde do que as mulheres? As explicações de homens com baixa escolaridade e homens com ensino superior. Cadernos de Saúde Pública, Rio de Janeiro, v. 23, p. 565-574, 2007.

HILDEBRANDT, Leila Mariza; ALENCASTRE, Marcia Bucchi. A inserção da psiquiatria no hospital geral. Revista Gaúcha de Enfermagem, Porto Alegre, v. 22, n. 1, p. 167, 2001.

\section{LOURAU, René. Análise Institucional e práticas de pesquisa-René Lourau na} UERJ. Rio de Janeiro: UERJ, 1993.

MACHADO, Vanessa; SANTOS, Manoel Antônio dos. O tratamento extra-hospitalar em saúde mental na perspectiva do paciente reinternado. Psicologia em Estudo, Maringá, v. 18, n. 4, p. 701-712, 2013.

MARCHEWKA, Tânia Maria Nava. A humanização na assistência à saúde mental no Hospital Geral: uma das alternativas terapêuticas da Reforma Psiquiátrica garantida pelos Direitos Humanos. Revista de Direito Sanitário, São Paulo, v. 8, n. 1, p. 43-6o, 2007.

MONTEIRO, Jaqueline da Rosa. Entre quatro paredes: desafios da atenção em saúde mental no hospital geral. 2013. Tese (Doutorado em Psicologia Social e Institucional)Programa de Pós-Graduação em Psicologia Social e Institucional da Universidade Federal do Rio Grande do Sul, Porto Alegre, 2013. Disponível em:

https://www.lume.ufrgs.br/handle/10183/107679. Acesso em: 5 mar. 2018.

MUSSE, Luciana Barbosa; PESSOA, Olívia Alves Gomes; SOUZA, Selma Leite do Nascimento Sauerbronn de. Entre judicialização e juridicização: por um Ministério 
Público resolutivo nas políticas públicas de saúde mental. Brasília (DF): Instituto de Pesquisa Econômica Aplicada, 2019. Disponível em:

http://repositorio.ipea.gov.br/bitstream/11058/9479/1/td_2524.pdf. Acesso em: 18 jun. 2020.

PAES, Marcio Roberto et al. O papel do hospital geral na rede de atenção à saúde mental no Brasil. Ciência, Cuidado e Saúde, Maringá, v. 12, n. 2, p. 407-412, 2013.

PAIVA, Rosemary Pinto do Nascimento et al. Análise do perfil de usuários atendidos em um centro de atenção psicossocial. J. Health NPEPS, p. 132-143, 2019.

SILVA, T. L.; MAFTUN, M. A.; KALINKE, L. P.; MANTOVANI, M. F.; MATHIAS, T. A. F.; CAPISTRANO, F. C. Perfil das Internações Hospitalares em Unidade psiquiátrica de um Hospital Geral. REME - Rev. Min. Enferm., Belo Horizonte, v. 18, n. 3, p. 644-651, 2014.

SOUSA, Fernando Sérgio Pereira de; JORGE, Maria Salete Bessa. O retorno da centralidade do hospital psiquiátrico: retrocessos recentes na política de saúde mental. Trabalho, Educação e Saúde, Rio de Janeiro, v. 17, n. 1, 2019.

VASCONCELOS, E. M. (org.). Abordagens Psicossociais. Reforma Psiquiátrica e Saúde Mental na Ótica da Cultura e das Lutas Populares. 2.ed. São Paulo: Hucitec, 2016.

WADI, Yonissa Marmitt; OLINTO, Beatriz Anselmo; CASAGRANDE, Attiliana De Bona. Filantropia, privatização e reforma: cenários da assistência psiquiátrica no estado do Paraná. História, Ciências, Saúde-Manguinhos, Rio de Janeiro, v. 22, n. 4, p. 1353-1371, 2015.

ZANARDO, Gabriela Lemos de Pinho et al. Internações e reinternações psiquiátricas em um hospital geral de Porto Alegre: características sociodemográficas, clínicas e do uso da Rede de Atenção Psicossocial. Revista Brasileira de Epidemiologia, São Paulo, v. 2o, p. 46o-474, 2017.

ZANELLO, Valeska; FIUZA, Gabriela; COSTA, Humberto Soares. Saúde mental e gênero: facetas gendradas do sofrimento psíquico. Fractal: Revista de Psicologia, Niterói, v. 27, n. 3, p. 238-246, 2015. 
Vandeléia Schinemann. Trabalhou na concepção e delineamento, análise e interpretação dos dados, redação e revisão crítica do artigo, aprovação da versão a ser publicada.

Doutoranda pelo Programa de Pós-Graduação Interdisciplinar em Desenvolvimento Comunitário da Universidade Estadual do Centro-Oeste. Graduada em Serviço Social pela Universidade Estadual de Ponta Grossa (UEPG). Assistente Social na Prefeitura Municipal de Prudentópolis (PR).

Gustavo Zambenedetti. Trabalhou na concepção e delineamento, análise e interpretação dos dados, redação e revisão crítica do artigo, aprovação da versão a ser publicada.

Doutor em Psicologia Social e Institucional (UFRGS). Professor do Departamento de Psicologia e do Programa de Pós-Graduação Interdisciplinar em Desenvolvimento Comunitário, Universidade Estadual do Centro-Oeste (/UNICENTRO).

Argum., Vitória, v. 12, n. 2, p. 141-164, maio/ago. 2020. | ISSN 2176-9575 